\title{
LOS PRINCIPIOS JURÍDICOS FUNDAMENTALES DE LA POTESTAD DISCIPLINARIA DE LA ADMINISTRACIÓN PÚBLICA EN CUBA
}

\section{THE FUNDAMENTAL LEGAL PRINCIPLES OF THE DISCIPLINARY POWER OF THE PUBLIC ADMINISTRATION IN CUBA}

\author{
Reynaldo Jorge LAM PEÑ ${ }^{1}$
}

\section{RESUMEN}

Ninguna forma de organización social, con independencia de su nomenclatura, puede funcionar sin normas de disciplina que rijan el actuar de sus miembros. La disciplinaes un fenómeno anterior al Derecho, impuesta capilarmente en los individuos. Es así, que, sin importar los cometidos de las formas de asociación, el ser humano necesita normas de conducta que limiten su libre albedrío y permitan la organización y funcionamiento de las diferentes estructuras a las que se integra, desde la dinámica de las relaciones sociales que surgen en su interior. En Cuba, La disciplina en un valor cardinal de las relaciones sociales, en especial de las relaciones de trabajo, con independencia del régimen jurídico al que se sometan los empleados. El presente artículo pretende una mirada al régimen jurídico aplicados al personal funcionarial al servicio de la Administración Pública, desde los principios jurídicos fundamentales que deben informar el ejercicio de la potestad jurídica administrativa disciplinaria, a saber: legalidad, tipicidad, proporcionalidad, culpabilidad, non bis in idem y tutela judicial efectiva.

Palabras claves: Disciplina. Potestad disciplinaria. Principios jurídicos.

\section{ABSTRACTS}

No form of social organization regardless of its nomenclature, can function without disciplinary rules governing the actions of its members. Discipline is a phenomenon prior to law, imposed capillary on individuals. It is like that, regardless of the forms of association, the human being needs norms of different structures to which it is integrated, from the dynamics of social relations that arise within you. In Cuba, discipline is a cardinal value of relationships social, specially labor relations, regardless of the legal regime to which employees submit. This article aims to take a look at the regime applied to civil servants at the service of the Public Administration, from the fundamental legal principles that should inform the exercise of the power disciplinary administrative law, namely: legality, typicity, proportionality, culpability, non bis in idem and effective judicial protection.

Keywords: Discipline. Disciplinary power. Legal principles.

\section{INTRODUCCIÓN}

Ninguna forma de organización social, con independencia de su nomenclatura, puede funcionar sin normas de disciplina que rijan el actuar de sus miembros. Desde una postura

\footnotetext{
${ }^{1}$ Master en Derecho Constitucional y Administrativo (Universidad de La Habana, 2020). Profesor Asistente de Derecho del Trabajo y de la Seguridad Social, Facultad de Derecho, Universidad de La Habana. Juez Profesional de lo Laboral. Tribunal Provincial Popular La Habana, Cuba.
} 
SegúnAlexy (1988,p. 143)los principios son:

«mandatos de optimización» ${ }^{5}$ que se caracterizan porque pueden ser cumplidos en diversos grados y porque la medida ordenada de su cumplimiento no solo depende de las posibilidades fácticas, sino también de las posibilidades jurídicas.

Consensuada es la existencia de los mismos y su presencia en el ordenamiento jurídico. Sin embargo, más allá de disquisiones sobre ello, lo importante, a los fines de esta investigación, es el valor y funciones de los mismos dentro del conjunto normativo de cualquier disciplina y en especial del Derecho Disciplinario Administrativo.Couselo(1971, p. 583) refiriéndose a los principios generales del Derecho señala que:

ocupan un lugar peculiar entre las fuentes, porque valen antes que la Ley, en la Ley y después de la Ley, parecen situados en tres planos, el iusnaturalista anterior a la creación legislativa, el político o sea dentro de esta última y el científico-técnico, en la elaboración doctrinaria, jurisdiccional.

Son reglas más generales que se aplican sobre la base de elementos cualitativos, pues segúnDworkin (2002, p. 72):

(...) no determinan una decisión, sino que proporcionan razones para hablar desde una $u$ otra posición. Significan en un sentido genérico, un conjunto de estándares, que no son normas, que apuntan siempre a decisiones exigidas por la moralidad o impelentes de objetivos que han de ser alcanzados. Se entienden semejantes a los valores, de ahí que en caso de una colisión entre principios la supremacía de uno sobre otro se entienda ligada a una superioridad de los valores que se encuentran tras dichos principios.

Variados han sido los autores ${ }^{6}$ que han escrito sobre las funciones de los principios del Derecho. Entre los distintos análisis existen elementos en común que sirven como base para, de manera breve, esbozar algunas de sus funciones. Entre la perspectiva funcional de los principios se puede hacer mención a la explicativa o sistematizadora. A través de esta funcionalidad del principio se precisa el entendimiento de una situación fáctica, desde el análisis de la norma y de la situación social, comprendiéndose el Derecho desde un fenómeno integral y no como un conjunto de normas aisladas. Asimismo, esto permite una argumentación de la situación compleja a partir de una conjugación de normas y principios para dar solución a las problemáticas jurídicas.

Otro de los postulados funcionales es su dimensión normativa. Este análisis parte de un enfoque sobre la consideración de los principios como fuente del Derecho y el reflejo de su papel en el ordenamiento jurídico. Así lo expreso Alberti (1996, p. 41), pues:

\footnotetext{
${ }^{5}$ Dicho autor continúa diciendo, para diferencias las posibilidades fácticas de las jurídicas que, el campo de las posibilidades jurídicas, está determinado a través de principios y reglas que juegan en sentido contrario, en cambio, las reglas son normas que exigen un cumplimiento pleno y, en esta medida pueden siempre ser solo cumplidas o incumplidas. Si una regla es válida entonces en obligatorio hacer precisamente lo que ordena, ni más ni menos. Vid.ALEXY, Robert. Sistema jurídico, principiosjurídicos y razón práctica en Doxa. Cuadernos de Filosofía del Derecho, n.5, p. 143-144, 1998.

${ }^{6}$ ARCE Y FLÓREZ-VALDÉS, Joaquín. Los principios generales del Derecho y su formulación constitucional.Madrid: Editorial Civitas. S. A., 1990. p. 59 y sgts; DWORKIN, Ronald. Los derechos en serio. Traducción de Marta Guastavino. 2. ed. Buenos Aires: Editorial Ariel S.A., 1989; DeL VeCCHIO G. Los principios generales del Derecho. Traducción de Juan Osorio Morales. Barcelona: Editorial Bosh, 1933; SARLO, Oscar et alias. La era de los principios: entre compromiso moral yretórica vacía. Análisis teórico y usos discursivos en el Derecho uruguayo. Montevideo: Fundación de Cultura Universitaria, 2018; TARdío PATO, José Antonio. Los principios generales del derecho. Su aplicación efectiva como normas jurídicas. Barcelona: Editorial Bosh, 2011; FernándeZ Bulté, Julio. Teoría General del Estado y el Derecho. Teoría del Derecho. Habana: Editorial Félix Varela, 2004. p. 234; GONZÁLEZ MONZÓN, Alejandro. Los principios generales del Derecho.Bogotá: Editorial Leyer, 2018. p. 369 y sgts.
} 
(...) hay principios que son reglas directas, y que como tales, pueden fundamentar una decisión, sin más justificación que la que prestan ellos mismos; hay principios que, al establecer un mandato finalista, limitan y habilitan la acción pública en un cierto (aunque vaporoso) sentido; hay principios, en fin, que contienen valores y que pueden indicar la posición o la actitud general que deben adoptar el intérprete y el operador jurídico para realizar su labor, aunque los contornos de tal posición resulten sumamente difuminados. Por tal motivo absurdo resulta desconocer la aplicabilidad directa de dichos principios del derecho y que fundamenta cualquier consideración sobre el análisis de sus funciones expuestas en estas líneas.

Por ende, citando a Monzón (2018, p. 405)estos- los principios-:

constituyen un elemento implícito, un conjunto de ideas sistemáticas inherentes a la esencia misma de lo jurídico, razón por la cual su atención no depende del mero reconocimiento de su vinculación jurídica en una estructuración formal de fuentes. Son construcciones que sistematizan, brindan sustento y coherencia, proyectan y racionalizan el orden de Derecho en una sociedad determinada, aunque claramente pueden ostentar el carácter de universales.

Otra de las funciones es su labor informadora e interpretativa ${ }^{7}$, la cual se vincula con lo expresado en párrafos precedentes. La función normativa de los principios se conjuga con la interpretativa pues esta tiene su punto de ebullición cuando la norma jurídica es interpretada en la labor aplicativa del Derecho. Esta función está encaminada a otorgarle sentido a la normativa jurídica taxativamente expuesta sobre papel. Los principios jurídicos ayudan a interpretar la intención de la norma, el valor tras las palabras.Ya lo expresaba,Bulté (2004, p. 234), al mencionar las funciones de los principios. Para este autor se podían entender tres de ellas, a saber:

(...) en un sentido de orientación y guía para la mejor interpretación de las normas jurídicas, desde una amplia dimensión axiológica; como criterios valorativos de gran absolutez, apoyaturas de los grandes fines del Derecho, que de ese modo permiten una orientación ética de sus normativas variables y para salvar lagunas legislativas.

Con todo, la función de los principios no es tan sólo subsidiaria o supletoria, como pudiera pensarse, pues, como advierte Castro (1984, p. 19), la función informadora del ordenamiento les otorga eficacia en toda labor interpretativa y aplicativa del Derecho.Para Atienza y Manero (1991, p. 101):

los principios cumplen con una función explicativa en dos sentidos: en primer lugar por su capacidad para sintetizar una gran cantidad de información: la referencia a unos pocos principios nos permite entender cómo funciona una institución jurídica en el conjunto del ordenamiento jurídico y en relación con el sistema local (...) en segundo lugar los principios nos permiten entender el Derecho- o los diferentes Derechos- no como un simple conjunto de pautas, sino como un conjunto dotado de sentido.

${ }^{7}$ La diferencia entre la función integradora y la función interpretativa de los Principios Generales del Derecho reside en que, en la función integradora, no existe norma-regla que aplicar (o sea norma con un supuesto de hecho más específico coincidente con el supuesto de hecho de la vida real de que se trata) y se aplica directamente el Principios Generales del Derecho en cuyo supuesto de hecho más genérico es subsumible el referido supuesto de hecho de la vida real. Sin embargo, en los casos de aplicación de un Principios Generales del Derecho con función interpretativa, sí que existe norma regla aplicable, pero, al permitir el desentrañamiento de su significado dos o más interpretaciones, se opta por la más conforme con el Principios Generales del Derecho de referencia, o incluso se utiliza un principio para interpretar otro. Vid. TARDÍO PATO, José Antonio. op. cit. p. 141. 
Si se traslada el tema en cuestión a la esfera del Derecho Administrativo se puede añadir según Matilla (2004, p. 110) que:

\begin{abstract}
el Derecho Administrativo es un campo muy fértil para la aplicación de los principios generales del Derecho, donde desempeñan un rol mucho más activo que el que pueden tener en el Derecho Privado. En la disciplina científica que nos ocupas los principios generales tienen una aplicabilidad importante sobre la base de las particularidades del proceso a través del cual, normativamente, ha sido construido el Derecho Administrativo, lo que ha desencadenado un grupo de normas jurídicas de variado grado de elaboración con una fuerte influencia de la potestad reglamentaria reconocida a la Administración Pública. De ahí la vital importancia de los principios generales del Derecho en el Derecho Administrativo, los cuales cobran más fuerza de cara a la potestad discrecional de que goza el ente público, como medidor de la impartición de justicia y la interpretación y aplicación del Derecho.
\end{abstract}

En igual sentido, es importante el papel de los principios, no solo en el Derecho Administrativo, sino en el ámbito del Derecho Disciplinario influenciado por la fuerza punitiva del Estado y la migración de principios y valores del Derecho Penal a la esfera disciplinaria. Este análisis pasa por el entendido de la semejanza de la potestad disciplinaria con el ius puniendi estatal y por tanto la homogeneidad de los principios jurídicos penales y los disciplinarios, a pesar de reconocérsele la flexibilidad que deben tener estos últimos sobre la base de la prontitud con que deben resolverse las cuestiones organizatorias de la Administración Pública. Castillo Blanco e Ildefonso Huertas (2002, p. 13) resumen dos posturas queanalizan el grado de homogeneidad entre los principios de ambas disciplinas de la siguiente manera:

A la tesis que defiende que hay un claro nexo común entre Derecho penal y Derecho sancionador, siendo ambas manifestaciones a distinta escala del ius puniendi del Estado, se le ha venido en denominar tesis cuantitativa. Por el contrario, a la que afirma la sustantividad del Derecho disciplinario, al que por consiguiente los principios penales sólo le son de aplicación analógica o supletoria, se le denomina tesis cualitativa.

En la disciplina penal los principios del Derecho no constituyen una fuente formal del derecho sobre la base del principio de nullum crimen sine lege(QUIROZ, 2003, p. 20). Sin embargo, son postulados que informan la labor sistematizadora e interpretativa del Derecho, informando las instituciones que la conforman sobre la base del papel que se le otorgue a los principios, no en el Derecho Penal en particular sino en el espacio que ocupa en el ordenamiento jurídico. De ahí la diferencia de Quirós (2003, p. 22)expresa, al analizar las fuentes del Derecho Penal, entre aquellas que provienen del sistema jurídico y las que le pertenecen a la dogmática penal.

Una diferenciación entre las distintas expresiones del poder punitivo o Derecho Sancionador, radican en evitar una saturación de sanciones que contengan los mismos mecanismos de control social y laceres presupuestos del Estado de Derecho. No obstante, dado que el mundo de las sanciones administrativas significa la mayor intromisión imaginable de la Administración en la esfera de la justicia, es necesario trasponer y aplicar los principios elaborados en el Derecho Penal, sino queremos que todas las garantías que otorga, proclama y predica el Estado Social de Derecho, se conviertan de forma caprichosa e injustificada en meros dogmas que pueden ser salvados al libre albedrio de cualquier poder público, simplemente calificando de administrativa una determina medida sancionadora (TRAYTER, 1992, p. 51).

Por ello, la importancia de un análisis de los principios jurídicos que informan la potestad disciplinaria de la Administración Pública sobre el funcionario público pues, se le otorga, a esta potestad administrativa, valores y mandatos reflejos de modos de actuación y de parámetros de justiciabilidad a tener en cuenta en el momento de la aplicabilidad de dicha institución jurídica en 
consonancia con otros que son expresión directa de la materia disciplinaria como reflejo del poder punitivo del Estado.

\section{LOS PRINCIPIOS JURÍDICOS FUNDAMENTALES QUE INFORMAN LA POTESTAD DISCIPLINARIA DE LA ADMINISTRACIÓN PÚBLICA EN CUBA}

\section{La configuración de la potestad disciplinaria de la Administración Pública está compuesta} por una variedad de normas jurídicas, algunas de las cuales han sido sustituidas recientemente, las cuales, amén de algunas diferencias, heredan similares patologías. El régimen jurídico funcionarial vigente en Cuba, está formado por la Constitución de la República de $2019^{8}$, el Decreto Ley No. 197/1999 (con sus modificaciones) "Sobre las relaciones laborales del personal designado para ocupar cargos de dirigentes y de funcionarios"'; la Ley 116/2013 "Código de Trabajo de la República de Cuba" "10; el Código de Ética de los cuadros del Estado y el Gobierno; y recientemente el Decreto Ley No. 13/2020 "Del Sistema de Trabajo con los cuadros del Estado y el Gobierno" "11 yel Decreto Presidencial No. 208/2021 "Reglamento del Sistema de Trabajo con los cuadros del Estado y el Gobierno y sus reservas"12, normativa, la primera, que derogo su antecesora $^{13}$.

Este marco regulatorio ofrece una difícil individualidad normativa de la potestad disciplinaria ${ }^{14}$, que entrelaza varios aspectos de los regímenes jurídicos de los funcionarios públicos y los trabajadores ordinarios. La regulación actual está caracterizada por deficiencias normativas y teóricas que repercuten en la conformación de un régimen disciplinario funcionarial consecuente con un marco estatutario de naturaleza pública y genera la dispersión de los elementos fundamentales de la potestad disciplinaria ${ }^{15}$. No obstante, desde la óptica de los principios jurídicos fundamentales, a saber, legalidad, tipicidad, culpabilidad, proporcionalidad, non bis in

${ }^{8}$ CUBA. [Constitución (2019)]. Constitución de la República de Cuba.Gaceta Oficial Extraordinaria, n. 5, 10 abr. 2019.

${ }^{9}$ CUBA. Decreto Ley $\mathrm{n}^{\circ} 197$ de 15 de octubre de 1999."Sobre las relaciones laborales del personal designado para ocupar cargos de dirigente y de funcionarios". Gaceta Oficial Extraordinaria, n. 4, 18 oct. 1999.

${ }^{10}$ CUBA. Ley n 116 de 20 de diciembre de 2013. "Código de Trabajo". Gaceta Oficial Extraordinaria, n. 29, 17 jun. 2014.

${ }^{11}$ CUBA. Decreto Ley n 13 de 18 de junio de 2020. "Del Sistema de Trabajo con los cuadros del Estado y el Gobierno".Gaceta Oficial Ordinaria, n. 30, 19 mar. 2021.

${ }^{12}$ CUBA.Decreto Presidencial no 208 de 4 de marzo de 2021. "Reglamento del Sistema de Trabajo con los cuadros del Estado y el Gobierno y sus reservas". Gaceta Oficial Ordinaria, n. 30, 19 mar. 2021.

${ }^{13}$ CUBA. Decreto Ley no 196 de 15 de octubre de 1999. "Sistema de trabajo con los cuadros del Estado y del Gobierno". Gaceta Oficial Extraordinaria, n. 4, 18oct. 1999. Derogado por la Disposición Final Cuarta del Decreto Ley 13/2020.

${ }^{14}$ Solo bastan verse en la literatura científica nacional mención a esta institución en particular en: GARCINI GUERRA, Héctor; ReYes Salía, Miguel. Derecho Administrativo. Parte General. Universidad de La Habana. La Habana, 1963. p. 157; Matilla Correa, Andry. Panorama General del Derecho Administrativo... op. cit. p. 475; MARTíNEZ GARcÍA, Yileisys. Potestad disciplinaria de la Administración Pública: aspectos teóricos generales”. In: Matilla Correa,Andry; Viteri NuÑEZ, Diego P. (Coord.) Reflexiones de Derecho Público. Habana: Editorial Unijuris, 2019.p. 78-105. t. 1. Asimismo, análisis sobre el régimen de responsabilidad disciplinaria de los funcionarios públicos en el período prerrevolucionario puede encontrarse en algunos autores. Para ello vid supra pie de página 180

${ }^{15}$ La potestad disciplinaria de la Administración Pública en Cuba es un tema de escaso tratamiento en la doctrina y difícil individualidad normativa, a partir del tratamiento otorgado en el ámbito iusadministrativo. Investigaciones científicas que tiene por objeto diversos aspectos del régimen jurídico funcionarial son: MONZÓN PÁEZ, Fernando.La noción de funcionario público como categoría iusadministrativa: una propuesta para Cuba.Tesis en opción al grado científico de Doctor en Ciencia Jurídica. La Habana, 2020; BATISTA TorRES, Jennifer. "La designación de los funcionarios públicos en Cuba". In: MATILlA CORREA, Andry (Coord.). Tendencias actuales de Derecho Administrativo. Homenaje al Dr. Héctor Garcini Guerra.La Habana: Ed. UNIJURIS, 2017. p. 341-353; SÁNCHEZ HERNÁNDEZ, Yohan. La definición de funcionario público en Cuba.Tesis (Maestría en Derecho Constitucional y Administrativo) - Universidad de La Habana, Habana, 2011; MARTíNEZ GARCÍAYileisys. op. cit. pp. 78-105. 
idem y tutela judicial efectiva, se pueden analizar los principales enunciados del régimen jurídico disciplinario vigente en el ordenamiento jurídico nacional, examen que representa un especial análisis de cara a la reciente normativa en la materia.

La existencia de los principios del Derecho en un ordenamiento jurídico depende de la concepción que se asuma del fenómeno jurídico. En Cuba ${ }^{16}$, más allá de las disquisiciones teóricas en torno a su reconocimiento como fuente del Derecho, se les atribuye valor como medio de interpretación. Sobre esta base, los principios en la ordenación patria aportan criterios valorativos axiológicos que contribuyan a la finalidad del Derecho (MONZÓN, 2018, p. 126). Su presencia en el marco jurídico adquiere un matiz mixto porque pueden estar presente taxativamente en algunas normas jurídicas generales, como la Constitución, o leyes particulares; mientras que otros se presuponen como parte de la cultura jurídica imperante, contribuyendo a ordenar y a encauzar las actuaciones jurídicas en la sociedad en tanto expresan postulados éticos, y respecto al cual han de desarrollar una función de guía, tanto en la creación jurídica cotidiana, como en la interpretación y en la propia creación judicial si se admitiese (PRIETO; MATILLA; PÉREZ et al., 2008, p. 53).

Sobre la base de estos presupuestos pueden trasladarse al régimen disciplinario de los funcionarios públicos, el análisis sobre los principios que, en esta investigación se consideran fundamentales para la regulación del régimen jurídico de la potestad disciplinaria de la Administración Pública, en aras de construir un marco jurídico garantista que aporte seguridad a los funcionarios públicos en el disfrute de sus derechos.

\section{a. Principio de legalidad}

El principio de legalidad en el ordenamiento jurídico cubano se interpreta desde la consagración del Estado cubano como un «Estado Socialista de Derecho y Justicia Social», con el cual la ordenación estatal está construida a partir del respeto a todo el conglomerado de normas jurídicas que contiene el ordenamiento jurídico. El artículo 7 constitucional, relativo la supremacía constitucional y, particularmente, el artículo 9, que establece el respeto, por los órganos del Estado, sus directivos, funcionarios y empleados, a la legalidad socialista ${ }^{17}$; configuran el principio de legalidad, más allá de la sumisión a la ley -sentido material-. El principio de

${ }^{16}$ Los principios del Derecho siempre han sido reconocidos en el ordenamiento jurídico cubano como medios de interpretación, sobre todo en manos de los órganos judiciales. Vid.CAÑIZARES, Fernando D. op. cit.p. 84-87; FERnÁNDEZ Bulté, Julio. Teoría del Estado y del Derecho. Teoría del Derecho. Segunda Parte. 2. ed. Habana: Ed. Félix Varela. 2004. p. 232-236; MATILla CORREA, Andry. "Comentarios sobre las fuentes del Derecho Administrativo (excepto el reglamento)". Temas de Derecho Administrativo Cubano. Habana: Ed. Félix Varela. 2004.p. 199-204. t. 1. ; PRIETO VALDÉS, Marta. "Artículo 7", en Comentarios al Código Civil Cubano. Disposiciones Preliminares. Libro Primero: Relación Jurídica. (Artículos 1 al 37).La Habana: Ed. Félix Varela, 2017. p. 113. t. 1. ; PRIETO VALDÉS, Marta. "El Derecho, la Constitución y la interpretación”. In: Perspectivas del Derecho Cubano actual.Madrid: Ed. Reus, 2006. p. 33-98. GonZÁLEZ MONZÓN, Alejandro. Los principios... op. cit. 2018.

${ }^{17}$ Sobre el desarrollo doctrinal del principio de legalidad en el contexto nacional Vid. ÁLVAREZ TABÍO, Fernando, et al.Legalidad y Justicia. (tres puntos de vista sobre el principio de legalidad).Biblioteca Jurídica de Autores cubanos y extranjeros.La Habana: Jesús Montoro Editor, 1952. v. 150.; CAÑIZAREZABELEDO, Fernando D. op. cit. p 200 y ss.; Escasena, José L. La evolución de la legalidad en Cuba.La Habana: Ed. Ciencias Sociales, 1990; FERNÁNDEZ Bulté, Julio, op. cit., pp. 155 y ss.; MATILla CORREA, Andry, "Notas sobre la ley y el principio de legalidad en el ordenamiento jurídico cubano". In: Memorias del VI Foro Iberoamericano de Derecho Administrativo. VIII Jornadas de Derecho Constitucional y Administrativo. Bogotá: Universidad Externado de Colombia, 2007. p. 411; ARIAS GAYOSO, Grethel, "La significación jurídica del principio de legalidad para la Administración Pública”. Andry MATILla CoRreA (coord.). In:Panorama de la Ciencia del Derecho en Cuba Estudios en homenaje al profesor DrC. Julio Fernández Bulté. Palma de Mallorca: Leonard Muntaner Editor, 2009. p. 165; FERRARI YAUNNER, Majela. "La legalidad como principio rector en la Constitución cubana. Reflexionando sobre sus retos".Revista Cubana de Derecho, Habana, n.50, p. 39, 2017. Su análisis particular en la esfera disciplinaria se puede encontrar en: CARMONA ROMAY, Adriano. Mis dictámenes en el Ministerio del Estado. Habana: Ed. Librería Martí, 1953. p. 43-44. 
legalidad se entiende como expresión de juridicidad, que impone la existencia de normas jurídicas que vinculan a la Administración cuando actúa y que de este modo la someten al Derecho ${ }^{18}$.

Los funcionarios públicos y órganos del Estado, donde se ubica la Administración Pública, actúan en el marco de sus respectivas competencias, de lo cual se entiende, la vigencia del principio de vinculación positiva de la Administración Pública en Cuba, enmarcando su actuación en lo que estrictamente le permita el ordenamiento jurídico, para lo cual la ordenación jerárquica también se establece como un principio de organización administrativa, en el artículo 101 e) y f) del texto magno cubano, en relación con la competencia como principio administrativo.

El principio de legalidad y la vinculación positiva a la Ley, representa para la materia disciplinaria administrativa, el reconocimiento y regulación de la potestad disciplinaria a través de la Ley; estableciendo la competencia a la autoridad administrativa correspondiente, tal como se configura en el artículo 33.1.2 del Decreto Ley 13/2020 y en elartículo 27 del Decreto Ley 197/1999; los que a su vez encuentran relación con el artículo 137 inciso w), por el cual el Consejo de Ministros o el Consejo Provincial (según el artículo $179 \mathrm{~m}$ ), como órganos ejecutivos y administrativos ejercitan aquellas atribuciones que le confiera la Constitución de la República, las leyes, la Asamblea Nacional del Poder Popular o el Consejo de Estado (a través de sus Decretos Leyes).

Expresión del principio de legalidad, no será solo la consagración de la potestad disciplinaria, sino también la regulación en Ley, de su contenido esencial; a saber: infracciones, sanciones disciplinarias y procedimiento disciplinario; a partir del principio de reserva de ley ${ }^{19}$. En Cuba el contenido de la potestad disciplinaria ha sido regulado por un Decreto Ley. El Decreto Ley es jerárquicamente inferior a la ley y se establecen diferencias entre ellos (PÉREZ, 2020, p. 42); a pesar de la posibilidad en su regulación legal de modificar leyes fruto del poder legislativo de la Asamblea Nacional del Poder Popular ${ }^{20}$. Esta norma posee efectos semejantes, pero no iguales a la Ley, aunque al ser disposiciones jurídicas que gozan dentro de la pirámide normativa de importantes posiciones, la armonía y coherencia entre ellas repercute en todo el ordenamiento jurídico. Si bien, las particularidades de la ordenación normativa antecesora configuraban el Decreto Ley de forma distinta $^{21}$, se defiende que la cuestión disciplinaria debe tener vocación de

${ }^{18}$ Ello guarda relación con los artículos 122 a), 128 a) 137 a), 144 a), 150, 179 a), 184 a), 191 a), mediante los cuales el Consejo de Estado, el Presidente de la República, el Consejo de Ministros, el Primer Ministro, los Tribunales, el Gobernador, el Consejo Provincial y la Asamblea Municipal del Poder Popular, respectivamente deben cumplir la Constitución y las Leyes.

${ }^{19}$ Sobre este particular, la doctrina patria ha defendido la imposibilidad de la configuración de tal principio en el ordenamiento jurídico cubano, como límite de regulación para el ejecutivo, a partir de la configuración de la unidad de poderes. PRIETO VALDÉS, Martha. "Reflexiones en torno al carácter normativo de la Constitución". HERNÁNDEZ, Lissette; PRIETO, Marta (comp.).Temas de Derecho Constitucional Cubano. Habana: Ed. Félix Varela, 2000. p. 31; PÉREZ LEGÓN, Orestes; GARCíA RUIZ, Joarlen. “¿Reserva de ley tributaria en el ordenamiento jurídico cubano? Notas inconclusas para un debate". In: MATILla CORREA, Andry(coord.). In:Panorama de la Ciencia del Derecho en Cuba. Estudios en homenaje al profesor DrC. Julio Fernández Bulté. Facultad de Derecho. Universidad de La Habana. Palma de Mallorca: Leonard Muntaner Editor, 2009. p. 486-493; PÉREZ MARTínEZ, Yuri. “¿Reserva de Ley en Cuba? A propósito de un debate". Matilla CorreA,Andry; Álvarez Tabío, Ana María (Coord.). In: El Derecho Público en Cuba a comienzos del siglo XXI. Homenaje al Dr. Fernando Álvarez Tabío.Habana: Ed. UH. 2011. p. 200-210.

${ }^{20} C f r$. Artículo 263. Ley No. 131 de 20 de diciembre de 2019, "Ley de organización y funcionamiento de la Asamblea Nacional del Poder Popular y el Consejo de Estado de la República de Cuba", en GOEx No. 6 de 16 de enero de 2020.

${ }^{21}$ Ello se relaciona con el contexto jurídico vigente en la Constitución de la República de 1976; donde si bien los DL no posee carácter de Ley, a partir del órgano del que emana, la práctica jurídica y la posibilidad de modificar leyes le otorgaban efectos jurídicos idénticos a la de la Ley. Anteriormente se establecía en un Acuerdo de la Asamblea Nacional del Poder Popularde diciembre de 1979, el cual puede consultarse en MARILL RIVERO, Emilio. Constitución de la República de Cuba. Habana: Ed. Ciencias Sociales, 1989. p. 224; VEGA VEGA, Juan. Derecho Constitucional Revolucionario en Cuba. La Habana: Ed. Ciencias Sociales, 1988. p. 257. MATILLA CORREA, 
ser regulada por ley. Ello, representa mayor seguridad jurídica para los destinatarios de sus normas pues sería aprobada por el órgano legislativo donde dimana el poder de pueblo, más cuando su regulación afecta derechos fundamentales de los funcionarios públicos, como es el derecho a desempeñar un cargo público ${ }^{22}$.

En cuanto a la permisión de cobertura reglamentaria, cuestión necesaria en la materia disciplinaria, se defiende que, en contexto nacional, no resultaría contra lege mientras respete las infracciones disciplinarias configuradas en el régimen disciplinario de los funcionarios públicos al que se hace referencia (GÓMEZ, 2004, p. 549).

Por tanto, la consagración del principio de legalidad en materia disciplinaria, se desprende del respeto de todos los órganos del Estado, incluida la Administración Pública al ordenamiento jurídico. La sumisión a la ley, debe entenderse en un sentido de juridicidad, donde se entrelacen cada una de las instituciones, órganos, agentes y funcionarios públicos.

Para Ferrari (2009, p. 231):

Significa una garantía de seguridad jurídicapara los funcionarios públicos que, a su vez, informa la configuración del resto de los principios jurídicos.

\section{b. Principio de tipicidad}

El principio de tipicidad en materia administrativa disciplinaria ${ }^{23}$ no encuentra en el marco constitucional regulación expresa ${ }^{24}$. Sin embargo, su fundamento parte del respeto a la ley, tal como refiere el principio de legalidad. Por ello, el enunciado relativo al cumplimiento de la legalidad socialista puede ser extendido para sustentar el principio de tipicidad como presupuesto para el ejercicio de la potestad disciplinaria. Los funcionarios públicos solo podrán ser sancionados si con su actuar incurren en alguna de las infracciones establecidas en la ley. Igualmente, la sanción a imponer debe corresponderse con las establecidas en la norma disciplinaria.

La subordinación de la tipicidad a la legalidad socialista, transmite la idea a los funcionarios públicos de que estos solo podrán hacer lo que expresamente les permite la norma jurídica (principio de vinculación positiva). Por ende, sus deberes públicos nacen de la ley ${ }^{25}$ y la autoridad disciplinaria solo podrá sancionar cuando se incurre en alguna de las infracciones que esta tipifica. El régimen disciplinario nacional establece una regulación taxativa de las

Andry. Comentarios sobre las fuentes... op. cit. p. 71. Posiciones contrarias fueron defendidas por: ÁLVAREZ TABÍO, Fernando. Comentarios a la Constitución Socialista. Habana: Ed. Pueblo y Educación, 1988. p. 295. Peraza Chapeau, José (Comp.). Selección de lecturas de Derecho Constitucional. Habana: Facultad de Derecho. Universidad de La Habana, 1985. p. 366.

${ }^{22}$ Cfr. Artículo 80 inciso h) de la Constitución de la República de 2019

${ }^{23}$ En Cuba no ha existido un amplio desarrollo doctrinal del principio de tipicidad en materia administrativa, salvo algunos ensayos limitados a la potestad sancionadora de la Administración. Vid. GóMEZ TrETO, Raúl. "La nueva legislación cubana de infracciones administrativas". Revista Jurídica, Habana, n. 9, 1985. VEGA VEGA, Juan. "Las contravenciones". Revista Cubana de Derecho, Habana, n. 33, ano 17, p. 27-48, 1988.; GÓMEZ PÉREZ, Ángela. Tutela legal... op. cit; ESPINOSA VELÁZQUEZ, Kenia. "El Derecho Administrativo Sancionador y el Derecho Penal: el problema de sus límites en el ordenamiento jurídico cubano". Tesis (Maestría en Derecho Constitucional y Administrativo) - Universidad de la Habana, Habana, 2011. Particularizado en la materia disciplinaria puede mencionarse a: DACOTA, Arístides; SMITH Carlos J. op. cit. p. 122; MARTínEz GARCÍAYileisys.

"Los recursos administrativos en materia disciplinaria en el ámbito de la Fiscalía General de la República de Cuba”. Tesis (Maestría en Derecho Constitucional y Administrativo) - Universidad de la Habana, Habana, p. 32-34, 2018.

${ }^{24}$ La CR no reconoce la tipicidad como principio constitucional, como se regulaba en la Constitución de la República de 1976 en su artículo 59 que, si bien se enfocaba en la materia penal, la doctrina nacional realizaba una interpretación extensiva atrayendo a todas las esferas de sanción. Vid. Artículo 58, Constitución de la República de 1976, con sus modificaciones de 1978, 1992 y 2002, en GOExNo. 3 de 31 de enero de 2003.

${ }^{25}$ Artículo 8 del Decreto Ley 13/2020. 
infracciones $^{26}$ y sanciones disciplinarias ${ }^{27}$ que se interrelacionan en dependencia de las circunstancias que puedan determinar la gravedad de las primeras, ya se consideren leves, graves o muy graves. En su regulación se emplean conceptos jurídicos indeterminados ${ }^{28}$, tipos disciplinarios abiertos ${ }^{29}$ e infracciones deontológicas ${ }^{30}$.

Se señala que se eliminó con la reciente normativa, la enunciación taxativa de aquellas infracciones que pueden considerarse graves, por el solo hecho de tipificarse, dejando entonces en manos de la autoridad disciplinario el juicio de proporcionalidad sobre la base de los elementos objetivos y subjetivos concurrentes en el hecho.

La ordenación de las infracciones en suelo patrio deben partir del presupuesto de que no siempre significan la ocurrencia de un daño material, sino también la vulneración de los deberes públicos inherente al cargo o función que desempeñe el funcionario público ${ }^{31}$. La relación entre la disciplina y los deberes públicos ${ }^{32}$, permite traer al terreno nacional el concepto de ilicitud sustancial como presupuesto para la configuración de las infracciones disciplinarias. Querrá esto decir que las infracciones disciplinarias son siempre reservorios de deberes propios del status funcionarial. Empero, la ausencia de un marco de deberes públicos propios de la función administrativa e inexistencia de un régimen jurídico determinado para la función pública, han impedido precisar el reservorio que particularice la función administrativa de los funcionarios públicos. Ello ha posibilitado la dispersión de su regulación en normas jurídicas de diferente jerarquía dando la posibilidad a la autoridad administrativa de estipular los deberes y prohibiciones de naturaleza pública que considere pertinentes. Resultado de ello, es el amplio abanico de tipos disciplinarios en blanco, que generan la remisión a otras normas jurídicas, de la que no se precisa su jerarquía. Por ende, si bien las faltas deben tener una relación directa con los deberes públicos, su ausencia, abre el diapasón para que sean regulados por la autoridad disciplinaria, cimentando un terreno incierto que determine las funciones particulares de cada funcionario público, y de cabida a la discrecionalidad de la autoridad disciplinaria para considerar vulnerado un deber. Se crea una inseguridad jurídica para el sujeto pasivo, al no poder encontrar en una norma específica de rango superior sus deberes fundamentales.

Cuestión aparte merecen las sanciones disciplinarias, para las cuales se establece un

${ }^{26}$ Artículo 29.1 del Decreto Ley 13/2020 y Artículo 19 del Decreto Ley 197/1999

${ }^{27}$ Artículo 30 del Decreto Ley 13/2020 y Artículo 20 del Decreto Ley 197/1999

${ }^{28}$ Los conceptos jurídicos indeterminados están regulados en el artículo 29 (DL 13/2020) en los incisos: Inciso b) «corrupción administrativa»; Inciso j) «mal uso de la autoridad»; Inciso m) «afectar el prestigio. imagen o valores de la entidad» y en el Artículo 31 «afectar sensiblemente el prestigio de la entidad y el suyo propio». Asimismo, en el artículo 19 (DL 197/1999) en los incisos: Inciso d) «mal uso de la autoridad»; Inciso j) «fines diferentes a los previstos»; Inciso n) «cualquier motivación ajena al interés social» y en el segundo párrafo del mismo artículo «conducta incompatible con el actuar de los principios éticos de un cuadro del Estado y el Gobierno».

${ }^{29}$ Los tipos abiertos están regulados en el artículo 29 (DL 13/2020) incisos: Inciso a) «incumplir la Constitución, reglamentos o cualquier otra norma jurídica o documento rector dictado que resulte de aplicación en la actividad en que laboran»; Inciso f) «disposiciones de seguridad y protección de la información oficial y seguridad informática»; Inciso h) «violar las disposiciones establecidas para el sistema de trabajo con los cuadros»; Inciso k) «incumplir normas del Sistema de control interno». Asimismo, en el artículo 19 (DL 197/1999) incisos: Inciso b) «disposiciones legales y reglamentarias dictadas para la actividad»; Inciso d) «negligencia en cumplimiento de funciones y atribuciones inherentes al cargo»; Inciso f) «retrasar los plazos establecidos»; Inciso h) «Incompatibilidades del cargo o actividad»; Inciso l) «no aplicar el procedimiento disciplinario» e Inciso m) «no aplicar controles establecidos en la responsabilidad colateral».

${ }^{30}$ Las infracciones deontológicas están reguladas e en el artículo 19 (DL197/1999) inciso k) «falta de honradez y honestidad».

${ }^{31}$ Aquellas que significan la ocurrencia de un daño a la entidad o terceros se conjuga con la responsabilidad material existente en el ordenamiento jurídico patrio a tenor del Decreto Ley No. 248 de 2007.

${ }^{32}$ El contenido de la infracción disciplinaria es lo que se asocia al principio de ilicitud sustancial. Vid.GómEZ Pavajeau, Carlos. "La ilicitud sustancial". In: Lecciones de Derecho Disciplinario. Colombia: Instituto de Estudios del Ministerio Público. Procuraduría General de la Nación, 2006. p. 17-39; RinCón CóRDOBA, Jorge I. La potestad disciplinaria en el Derecho Administrativo. Argentina: Ed. Ijinternational Legal Group, 2018. p. 122-147. 


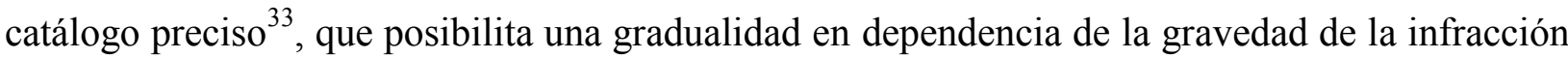
agrupadas en tres niveles: amonestación (privada o pública), demociones (temporales o definitivas) y separaciones definitivas (de la entidad o del sector o actividad).

El principio de tipicidad constituye uno de los aspectos más importantes del principio de legalidad que permite la exigibilidad de responsabilidad disciplinaria, de ahí la necesidad de su correcta articulación. Una regulación de lexcerta de sus infracciones y sanciones permite disminuir la discrecionalidad de la autoridad disciplinaria a los predios de determinar una sanción en base a la gravedad del ilícito, otorgando transparencia y seguridad jurídica al sujeto disciplinado.

\section{c. Principio de culpabilidad}

La culpabilidad se concibe como la otra cara de la responsabilidad disciplinaria /Ruiz y Gómez, 1935, p. 418). Si bien debe existir la vulneración del deber público tipificado en una infracción disciplinaria- elemento objetivo- se necesita la conducta dolosa o culposa del agente disciplinado. El desarrollo del principio ha sido olvidado por la doctrina nacional, siendo mayormente estudiado desde la dogmática penal ${ }^{34}$. Sin embargo, no puede ser relegado del resto de las sanciones que son expresión del ius puniendi, toda vez que constituye un presupuesto del Estado de Derecho.

El deber de sujeción voluntario a los deberes públicos, que conforman el orden disciplinario de los funcionarios públicos, permite establecer una presunción acerca de la prevalencia de la culpa en sus acciones y omisiones ilícitas. La negligencia sería un elemento incorporado en la vulneración de cada deber público a que vienen obligados. De esta manera, siguiendo la lógica discursiva de los elementos teóricos defendidos in supra, la culpabilidad será un elemento intrínseco en las infracciones disciplinarias, más allá de que en algunas, se tipifique una conducta dolosa o pueda servir de umbral para la exigencia de responsabilidad penal. El conocimiento de los deberes públicos que conforman la función administrativa del funcionario en cuestión, permite la exigibilidad de responsabilidad disciplinaria, no solo por la acción, sino por la omisión de cumplir con estos deberes.

Se puede resumir, que la individualidad de los deberes en cada sujeto, permite la exigibilidad personalísima de responsabilidad, excluyendo las formas de participación típicas del Derecho Penal. Con ello, merece un aparte la llamada «responsabilidad colateral» del contexto nacional. El artículo 29.2 ha traído al terreno nacional, heredado de sus normas antecesoras, un modificado concepto de responsabilidad colateral, el cual define como: "El cuadro es responsable colateral cuando, siendo superior jerárquico inmediato de los violadores o infractores y sin tener participación directa en los hechos, se demuestra que su falta de exigencia, su conducta negligente o por la no aplicación de los controles establecidos, facilitó la ocurrencia

\footnotetext{
${ }^{33}$ Cfr. Artículo 30 (DL 13/2020) y Artículo 20 (DL 197/1999).

${ }^{34}$ Desde el Derecho Penal puede verse: BAQUero Vernier, Ulises. Derecho Penal General. Facultad de Derecho. Universidad de Oriente, 1985. p. 94. t. 1. ; QuIRós PÍREZ, Renén. Manual de Derecho Penal Parte General. Habana: Ed. Félix Varela, 2004. p. 145-187. t. 2. ; ESTRADA CHACÓN, Mayrelis; GoITE PIERRE, Mayda; MÉNDEZ LÓPEZ, Mirna. "El principio de culpabilidad como elemento del delito en Cuba. Presupuestos para su reconfiguración teórica". Arnel MEDINA CUENCA y MaydaGoITE PIERRE (Coord.). Estudios sobre el Código Penal Cubano en el XXX Aniversario de su vigencia. Logros y perspectivas. Habana: Ed. UNIJURIS, 2018. p. 33-73. Desde el ámbito sancionador no ha sido tratado pues la responsabilidad ha sido configurada de forma objetiva. GÓMEz PÉREZ, Ángela. "Tutela legal a las contravenciones y los delitos paralelos en Cuba”. PÉREZ GAllardo, Leonardo B. et al. (coord.). Perspectivas del Derecho Cubano Actual. 1. ed. Madrid: Ed. Reus, 2006. p. 62. t. 1. ; CASTANEDOABAY, Armando. "Notas acerca de la responsabilidad administrativa. Instituciones y figuras jurídicas afines". Temas de Derecho Administrativo. Habana: Ed. Félix Varela,2004. p. 465. t. 2. Igualmente se pueden encontrar algunos análisis relacionados con la responsabilidad material de los funcionarios públicos en: FERNÁNDEZ-NESPRAL LÓPEZ, Ulises. "Responsabilidad Material y responsabilidad penal". Revista Cubana de Derecho, Habana, n. 33, ano 17, p. 49-68, 1988.
} 
de acciones violatorias de la disciplina por parte de los infractores o que, habiendo conocido de dichas violaciones e infracciones, no las enfrentó o no las informó de inmediato".

$\mathrm{Su}$ finalidad, no es hacer partícipe o cómplices a los superiores de los actos ilícitos de los subordinados, sino exigir por la omisión culposa (pues de ser dolosa podría incurrir en responsabilidad penal) de los deberes de control y vigilancia de las acciones de sus subordinados, que constituye un deber y un derecho propio del superior jerárquico. No obstante, estos esta figura, ha atentado contra una vigencia saludable del principio de culpabilidad. Sin tener en cuenta aquellas omisiones que en sí mismas constituyen deberes funcionales del jefe inmediato de los trabajadores, no puede significar una regla genérica a aplicar en todos los casos. El principio de culpabilidad se impone como una garantía del sujeto disciplinado que en la actualidad se ancla a la dignidad de los seres humanos. Se consagra como un presupuesto de justicia expresión del principio de presunción de inocencia, toda vez la subjetividad del funcionario graduará la gravedad de la sanción disciplinaria a imponer. Así, se conforma como una garantía del debido proceso porque supone la comprobación de la intención doloso o culposa del autor a través de un procedimiento establecido.

Esta presunción teórica, trascendente a los fines del ejercicio de la potestad disciplinaria, no ha sido regulada en la norma nacional, trayendo dificultades a la hora de aplicar una sanción disciplinaria y apreciar causas eximentes de la responsabilidad disciplinaria ${ }^{35}$, para lo cual no se pueden observar los preceptos penales, pues se incurriría en errores técnicos que desnaturalizan el Derecho Disciplinario. Este vacío normativo, otorga, una vez más, un margen indebido de discrecionalidad para la autoridad disciplinaria en el momento de aplicar una sanción disciplinaria. El análisis del elemento culposo representa uno de los elementos de la presunción de inocencia, que acompaña los procesos y procedimientos punitivos, de ahí que deba quedar demostrado, no solo el daño material, sino la culpabilidad del sujeto comisor, aspectos que deben acreditarse, junto a otros, en la fundamentación de la resolución sancionadora.

\section{d. Principio de proporcionalidad}

Otros de los elementos que se deben fundamentar suficientemente en la resolución disciplinaria en justeza y proporcionalidad de sanción a imponer. De ahí la importancia del principio de proporcionalidad para el régimen jurídico de la potestad disciplinaria. El ordenamiento nacional carece de un desarrollo teórico en torno a la proporcionalidad en sede administrativa $^{36}$. Empero, su adecuada regulación establece parámetros limitativos a una

\footnotetext{
${ }^{35}$ Se debe tener en cuenta la concurrencia de causas de caso fortuito o fuerza mayor; la ponderación, cuando entran en juego dos deberes funcionales del funcionario públicos, o un deber público y una orden jerárquica, o u derecho fundamental del funcionario. Asimismo, sostiene que no pueden invocarse otras como el error de derecho, o inmadurez psicológica pues la especial relación en que se encuentra el funcionario, necesita de análisis de idoneidad y evaluaciones desempeño, que lo hicieron apto mentalmente para el cargo.

${ }^{36}$ En el marco jurídico administrativo, el principio de proporcionalidad no ha constituido centro de debate, pues los principales debates en cuestiones sancionadoras o disciplinarias han girado mayormente sobre el principio de legalidad. Vid. RUIZ y GÓMEZ, Julián. Principios del Derecho Administrativo... op. cit.p. 84-87; GARCINI GUERRA, Héctor. Derecho Administrativo. 2. Ed.Habana: Ed. Pueblo y Educación, 1986. p. 165-167.; GóMEZ PÉREZ, ÁngelaEl principio non bis in ídem. Sanciones penales y sanciones administrativas.Bolivia: Fondo Editorial Colegio de Abogados de Cochabamba, 2001.; EsPINOSAVELÁzQUEZ, Kenia. "El Derecho Administrativo Sancionador y el Derecho Penal:el problema de sus límites en el ordenamiento jurídico cubano". Tesis (Master en Derecho Constitucional y Administrativo) - Universidad de la Habana, Habana, 2011. p. 57-77; MARTÍNEZ GARCÍA, Yileisys. Los recursos administrativos... op. cit. pp. 34-35. No obstante, ha existido algún pronunciamiento en torno al mismo desde el Derecho Penal o el Derecho del Trabajo que, si bien no realizan un desarrollo teórico, si reconocen su expresión en las normativas patrias. Vid.MEDINA CUENCA, Arnel."Los principios de intervención mínima, proporcionalidad y resocialización en la era del expansionismo penal". Carlos A. Mejías (Coord.). Temas de Derecho Penal Parte General. Libro Homenaje al Profesor Renén Quiroz Pírez.Camagüey: Ed. My. Gral. Ignacio Agramonte y Loynaz. 2015. p. 55-92; VIAMONTES GuILBEAUX, Eulalia de la C. Derecho Laboral... op. cit. p. 316-317.
} 
discrecionalidad de la autoridad disciplinaria ${ }^{37}$. La atipicidad en materia disciplinaria de no estructurar la norma jurídica a partir de la hipótesis y su correlativa sanción, incrementa la actuación discrecional en la imposición de la sanción, la cual solo puede ser intervenida desde el establecimiento de criterios reglados. No obstante, se resalta que la potestad disciplinaria no es una potestad discrecional, a pesar de conceder un marco de actuación que depende de valoraciones precisas en torno al ilícito disciplinario.

La proporcionalidad no posee una regulación constitucional expresa. No obstante, de la letra del artículo constitucional 94 inciso e), relativo a la obligatoriedad de una resolución fundada para privar de derechos a las personas, puede interpretarse, que la razonabilidad y motivación de los actos administrativos disciplinarios a funcionarios públicos es un derecho inherente al debido procedimiento (DACOTA; SMITH, 1927, p. 129), ya que estas constituyen aristas del principio de proporcionalidad.

El marco jurídico disciplinario por su parte se determina taxativamente que para la imposición de medidas disciplinarias ha de atenderse a la correspondencia entre la gravedad de las infracciones cometidas y severidad de la sanción a imponer. Se configurarse dos momentos donde la autoridad puede aplicar criterios discrecionales: en la determinación de la gravedad de la infracción y en la aplicación de la medida disciplinaria. Para reglar dicha discrecionalidad, en el primer momento, la norma determina algunas infracciones que pueden considerarse graves como aquellas que son reflejo de hechos de corrupción administrativa, o los que atenten contra bienes de la entidad o de terceros.

Para el caso de la sanción a imponer se establecen criterios objetivos (importancia y gravedad de la infracción disciplinaria, daños y perjuicios causados, circunstancias concurrentes, trascendencia) y subjetivos (historia laboral, conducta actual del infractor y la actitud del mismo ante los hechos) de valoración.

En el marco disciplinario la proporcionalidad alcanza una configuración distinta ${ }^{38}$ a partir de la imposibilidad de establecer una estructura normativa de hecho y sanción. El principio de proporcionalidad puede analizarse en la concepción de la norma y en la aplicación de la misma aplicando un juicio de proporcionalidad basado en los tres elementos que, teóricamente, componen el principio. El primero comprende el análisis de medio a fin a partir del objetivo perseguido con la actuación administrativa y la sanción impuesta. La necesidad descansa en la idoneidad de la sanción disciplinaria escogida a partir de la razonabilidad de que constituye la menos gravosa para el funcionario disciplinado en la búsqueda de la restauración de la organización administrativa. Por último, la proporcionalidad en sentido estricto es una ponderación entre los beneficios y riesgos de la imposición de la sanción.

La regulación actual no establece un valor al momento de ponderar los criterios reglados en la determinación de la sanción, sino que quedan en manos de la fundamentación del disciplinante, los cuales, con acierto, deben obligatoriamente ser llevados a la resolución disciplinaria, donde debe precisarse, mediante la motivación del acto administrativo, la idoneidad y necesidad de la sanción disciplinaria a imponer. La razonabilidad de la sanción disciplinaria constituye el

\footnotetext{
37 Sobre el reconocimiento del principio de proporcionalidad como límite a la discrecionalidad. Vid.MARCHECO ACUÑA, Benjamín. "El control judicial de la potestad discrecional de la Administración Pública en Cuba".Revista Facultad de Derecho y Ciencias Políticas, v. 39, n. 110, p. 71-73, 2009.; ARIAS GAYOSO, Gretel. "A vueltas con la discrecionalidad administrativa”. Revista NovumJus, Colombia, v. 4, n. 1, p. 146, 2010.

${ }^{38}$ Vid. DurÁn MARTíneZ, Augusto. Estudios de Derecho Administrativo. Parte general. Montevideo: MastergrafSRL. 1999. p. 305-306; ROA SALGUEDO, David. "El principio de proporcionalidad: cortapisa al abuso de la potestad disciplinaria”.Revista de Ciencias Penales y Criminología, Colombia, v. 35, n. 99, p. 139-156, 2014.; TIRADO BARRERAS, José Antonio. "Principio de proporcionalidad y sanciones administrativas en la jurisprudencia constitucional". Revista Derecho PUCP,Perú, n. 67, 2011.; OCAMPO VÁZQUEZ, Fernando. "El principio de razonabilidad como límite a la tipificación reglamentaria de los Organismos Reguladores".Revista Ius et veritas, Perú, n.42, p. 290-304, 2011.; LÓPEZ LÓPEZ,Sandra M. “Aplicación de los principios de proporcionalidad y legalidad en el derecho disciplinario al momento de la tasación de la sanción disciplinaria para los funcionarios de la rama judicial". ViaInveniendi et Iudicandi,Colombia, p. 129-161, 2018.
} 
momento culminante donde se aplican la triada de principios legalidad-tipicidad-culpabilidad, la cual podrá ser sometida posteriormente a mecanismos de reclamación y control.

\section{e. $\quad$ Principio de non bis in idem}

El principio de non bis in idem, no encuentra un reconocimiento expreso en la legislación nacional, lo que no desmerita que sea enunciado y acogido sobre la base de los principios del Derecho $^{39}$. La doctrina nacional ${ }^{40}$, ha reconocido la posibilidad de exigir a los funcionarios públicos, responsabilidad penal, civil, administrativa, política o, más recientemente en el tiempo, material ante idénticos hechos.

La ordenación disciplinaria específica reconoce la posibilidad de doble imposición de sanción $^{41}$. Para ello establece como presupuestos un término de prescripción de 5 años para exigir la responsabilidad disciplinaria de un hecho que pueda ser constitutivo de delito mientras el funcionario desempeñe el cargo designado. Igualmente, se establece la posibilidad de la autoridad disciplinaria de invocar la responsabilidad penal a partir de criterios de oportunidad, cuando el funcionario no labora en la función administrativa que se encontraba al momento del ilícito. Dicho precepto responde a la finalidad del ejercicio punitivo, pues si el agente comisor no posee el mismo cargo, no representa riesgo para la función administrativa y, por ende, no cumple finalidad la aplicación de la sanción disciplinaria.

El non bis in idem puede analizarse desde una visión material o formal. Desde la arista material $^{42}$, se ha expresado la diferencia de fundamentos entre la responsabilidad penal o disciplinaria, lo cual puede generar la imposición de sanciones de distinta naturaleza. La potestad disciplinaria se ejerce cuando se atenta, desde la vulneración de un deber público, que lesiona la organización administrativa que mantiene el correcto funcionamiento del aparato público. Los bienes jurídicos penales protegen varias esferas del ente administrativo o la sociedad desde una lesividad mayor a la comunidad social. Para el caso de la colisión de responsabilidad disciplinaria y material, se sostiene que esta última se encamina al resguardo de los bienes de las entidades, desde una perspectiva económica. En ambos supuestos pueden confluir identidad de sujetos y hechos, pero los bienes jurídicos que se protegen con la responsabilidad penal o material distan de los fundamentos que sostienen la responsabilidad disciplinaria.

No obstante, surgen interrogantes a partir de una integración del ordenamiento jurídico. Se puede analizar, sobre los axiomas de la proporcionalidad, la necesidad e idoneidad de una doble sanción cuando se cometen delitos funcionariales (MEJÍAS, 2010) y además se impone como sanción

${ }^{39}$ Vid. GoITE PIERRE, Mayda. "Principios e Instituciones de las Reformas Procesales en América Latina: seguridad jurídica, non bis in idem, cosa juzgada y revisión penal". In: MEDINA CUENCA,Arnel(coord.).Expansionismo, nuevas formas de criminalidad y proceso penal en los inicios del siglo XXI. La Habana: Ed. UNIJURIS, 2014 p. 258.Serie Ciencias Penales y Criminológicas, 2. También sobre la materia puede consultarse: GóMEZ PÉREZ, Ángela. El principio de non bis in idem... op. cit. y particularmente en la esfera disciplinaria:RUIZ Y GÓMEZ, Julián. Principios ... op. cit. p. 423; MARTÍNEZ GARCÍAYileisys. Los recursos administrativos... op. cit. pp. 35-36.

${ }^{40}$ Vid.Govín Y TORRes, Antonio. Elementos Teóricos Prácticos del Derecho Administrativo vigente en Cuba. 2. ed. La Habana: Imprenta "El Siglo XX”, 1914.; LANCÍs Y SÁNCHEZ, Antonio; MARTíneZ SÁENZ, Joaquín. Ensayos de Derecho Administrativo.La Habana: Imprenta y Papelería de Rampla y Bouza y Co.,1922. t. 1. ; RuIZ Y GómeZ, Julián. Principios... op. cit.; DAcotA, Arístides; Smith Carlos J. op. cit. VeGA VeGA, Juan. El sistema jurídico de la disciplina social..La Habana. Unión Nacional de Juristas de Cuba, 1984. Colección de Estudios Jurídicos.

${ }^{41}$ Cfr. Artículo 38.2 (DL 13/2020); Artículo 26 (DL 197/1999) (confluencia de responsabilidad penal y disciplinaria); Artículo 16, tercer párrafo (DL 248/2007) (confluencia de responsabilidad material y disciplinaria).

${ }^{42}$ MEJÍAs RoDRÍGUEZ ha expresado que: “(...) la distinción entre uno «la responsabilidad penal» y otro Derecho sancionador «el autor abarca dentro de Derecho sancionador la potestad disciplinaria (p. 21)» impone no confundir normas que, si bien sancionan las infracciones y deberes en el ámbito de la economía, indiscutiblemente tutela intereses distintos, ya que, como parte de su naturaleza y objeto, el Derecho Administrativo Sancionador tiene carácter punitorio y tutela un fin administrativo (...)" (las explicaciones entre guiones son aclaraciones del autor). Vid.MejíAs Rodríguez, Carlos A. Derecho Penal Económico.La Habana: Ed. Félix Varela,2016. p. 18-24. 


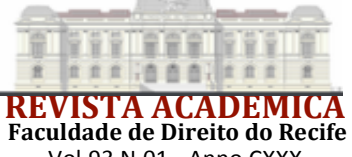

Vol.93 N.01 - Anno CXXX

accesoria la privación del ejercicio de profesión cargo u oficio ${ }^{43}$, toda vez que la misma le impedirá al funcionario desempeñar el cargo público, y puede resultar excesiva la sanción disciplinaria, ya que con la sanción accesoria, a consideración del autor, se protege idéntico fundamento: la organización administrativa.

La arista formal, hace referencia al doble procedimiento. La posibilidad de doble sanción, desencadena dos procedimientos previos. Sin embargo, la norma no aclara cuestiones relativas al valor de cada uno. Algunos autores en su momento, defendieron la inhibición del procedimiento administrativo frente al penal, o la exoneración por vía administrativa frente a una exoneración penal. Sin embargo, son los presupuestos teóricos los que pueden despejar las variables al respecto. La independencia de objetos de protección, le atribuye valores iguales a cada uno de ellos, que no necesitan entrar en contradicción. Por ello, se considera que no debe ponderar uno sobre otro. Empero, desde la congruencia, es necesario precisar que no resulta coherente que un mismo hecho, quede probado para el proceso penal y no para el procedimiento disciplinario y viceversa, toda vez que la materialidad de hecho es una sola. Por tanto, cuando las líneas que delimiten la responsabilidad son confusas se propone la paralización del procedimiento disciplinario, hasta que se concluya el penal, en atención a los hechos probados por esta. (MARINA, 2020, 441)

\section{f. Principio de tutela judicial efectiva}

La tutela judicial efectiva ha sido uno de los aspectos más esperados y recientes por la doctrina nacional ${ }^{44}$. Es una de las mayores novedades en el reciente texto constitucional. Su consagración como un derecho constitucional ${ }^{45}$, genera el atemperamiento de todo el ordenamiento jurídico. Una de las materias más beneficiadas será la contenciosa administrativa pues el papel que ha desempeñado la función de los tribunales frente a la actividad administrativa, ha estado influenciado por condicionantes históricas, que hoy, desde una mirada contemporánea no se corresponde con los principios jurídicos que debe informar un Estado de Derecho (AZCUY, 2010, p. 284).

El régimen jurídico disciplinario de los funcionarios públicos necesita reacomodar sus presupuestos, para consagrar el derecho a la tutela judicial efectiva, una vez agotada la vía administrativa como expresión de la dignidad del ser humano (GUZMÁN, 2020, p. 167). Este principio constituirá el eslabón indispensable entre el debido procedimiento y la buena administración. Igualmente, será un mecanismo de control judicial para la potestad disciplinaria de la Administración Pública, que se unirá a las limitaciones que generan los principios jurídicos analizados hasta el momento.

Aplicando los elementos que componen la tutela judicial efectiva, se puede decir que en materia disciplinaria no se reconoce el derecho de acceso a la justicia. Si bien, no existe una

${ }^{43}$ Cfr. Artículo 39, Ley No. 62 de 1987, “Código Penal”. Sobre los fundamentos de la sanción puede verse: QuIROZ PíREZ, Renén. Manual de Derecho Penal.La Habana: Ed. Félix Varela,2015. p. 166-176. t. 1. Parte 2.

${ }^{44}$ Vid. CARrasco CASí, María. "El acceso a la justicia en el Derecho Administrativo". Revista Justicia y Derecho, Habana, n. 7, p. 20-29, 2006.; ARIAS GAYOSO, Gretchen; BORGES FRÍAs, Jorge L. "La justicia administrativa en Cuba". Disponible en:http://www.avizora.com/publicaciones/derecho/textos/0030 justicia_administrativa_cuba.htm; RICHARDS MARTínEZ, Orisell. "El agotamiento de la vía administrativa como presupuesto de acceso a la justicia administrativa. Algunas consideraciones desde Cuba". In: MATILlA,Andry; MendozA, Juan;MANTECóN, Ariel (coord.). In:Perspectiva actual del Derecho Procesal (civil y administrativo) en Cuba. Homenaje al profesor Dr. Rafael Grillo Longoria.Habana: Ed. ONBC, 2016. p. 344-350. Otros temas procedimentales han sido abordados por:DíAZ TENREIRO, Carlos M. "El procedimiento administrativo". Revista Justicia y Derecho, Habana, Año 12, n.22, p. 50-69, 2014.; VALDÉS ROSABAL, Kenia. "El control de la potestad discrecional de la administración”. Revista Justicia y Derecho, Habana, Año 12, n. 22, p. 70-87, 2014.

${ }^{45}$ Cfr. Artículo 92, CR de 2019. 


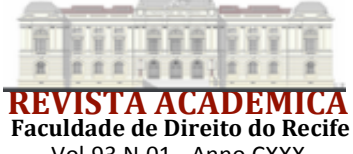

Volde de Direito do Recife

Vol.93 N.01 - Anno CXXX

negativa expresa, la interpretación de la ordenación jurídica al respecto lo evidencia ${ }^{46}$. Se han sustentado la negativa también haciendo referencia al apartado 4 del artículo 657 de la LPCALE $^{47}$, relativo a la exclusión de la jurisdicción contenciosa de las materias constitucionales, civiles, penales, laborales y de seguridad social, sobre la base del conocimiento de los asuntos por la jurisdicción laboral. Válido resulta aclarar, sobre la base de los elementos teóricos esbozados en torno al régimen jurídico funcionarial, que el mismo no posee naturaleza laboral, salvando la existencia de aquellos derechos en el trabajo ${ }^{48}$, de titularidad de los funcionarios. Por ende, su régimen disciplinario no posee naturaleza laboral, sino administrativo, a partir; de la ratio de los deberes públicos y las características de la relación jurídica funcionarial que configuran las infracciones disciplinarias y, consecuentemente, debe conocer la jurisdicción contenciosa administrativa. Asimismo, tampoco debe sostenerse la exclusión sobre la base de la discrecionalidad $^{49}$ de la potestad disciplinaria.

El reconocimiento del acceso a la justicia, también necesitaría valorar el agotamiento previo de la vía administrativa ${ }^{50}$, para acceder al órgano judicial. Tomando las ideas de RICHARDS, (2018, p. 144).

(...) se necesita valorar la pertinencia del carácter facultativo de la regla de agotar la vía administrativa (...) sobre la base de la construcción de un diseño que permita balancear los intereses individuales y colectivos para la completaprotección jurídica de los administrados".

El procedimiento contencioso administrativo es un acto de control de legalidad, y por ende debe operar sobre las potestades jurídicas administrativas de la Administración Pública. La negativa de acceso a la justicia para los funcionarios públicos, afecta, por transitividad, la valoración de los elementos asociados al derecho a la defensa, la posibilidad de acceder a iguales armas procesales y la ejecutoriedad de la sentencia judicial. Desmerita el derecho a la igualdad de todos ante la ley, reconocido en el precepto 42 constitucional, limitando el acceso a la justicia. La efectividad de la tutela se refleja en el debido proceso ${ }^{51}$ que debe informar la actuación de los órganos judiciales.

\section{CONCLUSIONES}

Sobre la base de los elementos teóricos y normativos analizados en el presente artículo se puede arribar a las siguientes conclusiones

1. El régimen jurídico de la potestad disciplinaria es informado por un amplio catálogo de principios jurídicos generales, otros propios del Derecho Administrativo y los inherentes a la

${ }^{46} C f r$. Los artículos 36.3 (DL 13/2020) y 27 segundo párrafo (DL 197/1999) establecen que cuando la medida es impuesta por el jefe máximo del órgano únicamente procederá recurso de reforma.

${ }^{47}$ Cfr. Ley No. 7 de 19 de agosto de 1977, Ley de Procedimiento Civil, Administrativa, Laboral y Económica, en GOO No. 34 de 20 de agosto de 1977, modificada por el DL No. 241 de 26 de septiembre de 2006, en GOEx. No. 33 de 27 de septiembre de 2006.

${ }^{48}$ Para los derechos en el trabajo, si es competente la jurisdicción laboral, para los funcionarios públicos receptores del Decreto Ley 197/1999 a tenor del artículo 3.

${ }^{49}$ Se ha planteado en epígrafes anteriores que la potestad disciplinaria no es discrecional. Asimismo, tampoco puede tomarse como referencia para alegarla la aplicación de conceptos jurídicos indeterminados o la calificación de los hechos, pues en dichos elementos operan otros principios como la

legalidad, tipicidad, culpabilidad y proporcionalidad. Vid.GARCÍA DE ENTERRÍA, Eduardo; FERNÁNDEZ-

ROMÁn, Tomás. op. cit. Tomo I. p. 483-484; MARCHECO ACUÑA, Benjamín. Fundamentos... op. cit.

pp. 219-221.

${ }^{50}$ El agotamiento previo de la vía administrativo está dispuesto por el Dictamen No. 61 de 1979 del Consejo de Gobierno del Tribunal Supremo Popular, contenido en el Acuerdo No. 204 de 30 de abril de 1979.

${ }^{51}$ El debido proceso se regula en el artículo 94, Constitución de la República, bajo los mismos fundamentos del debido procedimiento. 


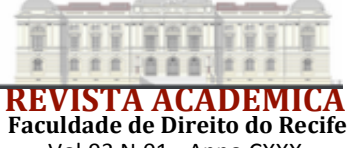

voldade de Direito do Recife

Vol.93 N.01 - Anno CXXX

cuestión disciplinaria que contribuyen al sustento de garantías sustantivas y procesales de los derechos subjetivos adquiridos por los funcionarios públicos.

2. Algunos de los principios jurídicos fundamentales que deben informar la potestad disciplinaria de la Administración Pública en pos de su correcta aplicación y la configuración de un régimen jurídico disciplinario que otorgue garantías y seguridad jurídica a los funcionarios públicos que cometan ilícitos disciplinarios son: el principio de legalidad, el principio de tipicidad, el principio de culpabilidad, el principio de proporcionalidad, el principio de non bis in idem y el principio de tutela judicial efectiva.

3. En el ordenamiento jurídico administrativo cubano no están definidos los principios jurídicos fundamentales que deben informan la potestad disciplinaria de Administración Pública en pos de su adecuado ejercicio y ofrecer garantías sustantivas y procedimentales a los funcionarios públicos disciplinados.

4. Algunos de los principios jurídicos fundamentales que deben informar la potestad disciplinaria de la Administración Pública en Cuba deben responder a los particulares analizados, teniendo en cuenta el respeto a la ordenación jurídica, la vocación de tipificar en Ley las infracciones y sanciones disciplinarias según los presupuestos objetivos y subjetivos que permitan un adecuado análisis de las circunstancias personales y materiales del ilícito disciplinario; así como la posibilidad del doble juzgamiento y un procedimiento disciplinario que cumpla con las garantías procedimentales y de defensa del funcionario público reconociendo el derecho de acceso a la justicia y el debido proceso en vía contenciosa administrativa.

\section{REFERENCIAS}

ALBERTI, E. El derecho por principios: algunas precauciones necesarias (Debate sobre El Derecho dúctil, de Gustavo Zagrebelsky). In:ANUARIO de Filosofía del Derecho, Nueva Época. Madrid: Centro de Publicaciones del Ministerio de Justicia, 1996. t. 13-14.

ALEXY, Robert. Teoría de los Derechos fundamentales. Madrid: Centro de Estudios Constitucionales, 1993.

AtIENZA, Manuel;MANERo, JuanRuiz. Sobre principios y reglas, en Doxa. Cuadernos de Filosofía del Derecho,n. 10, 1991.

AZCuY, Hugo. Análisis de la Constitución Cubana y otros ensayos. Habana: Ruth Casa Editorial, Instituto Cubano del Libro, 2010. p. 284.

Castanedo Abay, Armando et al.Temas de Derecho Administrativo Cubano. Habana: Ed. Félix Varela 2004. t. 1.

CASTILlo Blanco, Federico;Ildefonso Huertas, Rosa María. La renovación de la dogmática del Derecho Disciplinario: A propósito de las infracciones y sanciones en el personal estatutario de la Seguridad Social.Revista de Administración Pública,Madrid, n. 158, 2002.

CUBA. Constitución de la República de Cuba de 2019.Gaceta Oficial Extraordinaria, n. 5, 10 abr. 2019.

CUBA. Decreto Ley n ${ }^{\circ} 13$ de 18 de junio de 2020. "Del Sistema de Trabajo con los cuadros del Estado y el Gobierno”. Gaceta Oficial Ordinaria, n. 30, 19 mar. 2021.

CUBA. Decreto Ley no 197 de 15 de octubre de 1999.“Sobre las relaciones laborales del 
personal designado para ocupar cargos de dirigente y de funcionarios". Gaceta Oficial Extraordinaria, n. 4, 18 oct. 1999.

CUBA. Decreto Presidencial no 208 de 4 de marzo de 2021. "Reglamento del Sistema de Trabajo con los cuadros del Estado y el Gobierno y sus reservas". Gaceta Oficial Ordinaria, n. 30, 19 mar. 2021.

CUBA. Ley n ${ }^{\circ} 116$ de 20 de diciembre de 2013. "Código de Trabajo". Gaceta Oficial Extraordinaria, n. 29, 17 jun. 2014.

Dacota, Arístides; Smith Carlos J. Apuntes de Derecho Administrativo. (adaptado a las explicaciones de clases). Habana: Imprenta y Papelería La Universal, 1927.

DíAz Couselo, José María. Los Principios Generales del Derecho. Buenos Aires: Editorial Plus Ultra, 1971.

DurÁn MARTíneZ, Augusto. Estudios de Derecho Administrativo: parte general. Montevideo: MastergrafSRL, 1999.

DwORKIN, Ronald. Los derechos en serio. Barcelona: Editorial Ariel, 2002.

Fernández Bulté, Julio. Teoría del Estado y del Derecho. Teoría del Derecho. Segunda Parte. Habana: Ed. Félix Varel, 2004. p. 232-236.

FERRARI YAUNNER, Majela. "Seguridad jurídica y legalidad”. In: CORREA, Andry Matilla (coord.). Panorama de la Ciencia del Derecho en Cuba. Estudios en homenaje al profesor DrC. Julio Fernández Bulté. Palma de Mallorca: Leonard Muntaner Editor,2009.

FouCAult, M. El poder psiquiátrico. Buenos Aires: Fondo de Cultura Económica, 2007.

Garcini Guerra, Héctor. Derecho Administrativo. 2. ed.Habana: Ed. Pueblo y Educación, 1986.

Gómez Pavajeau, Carlos. "La ilicitud sustancial”, en Lecciones de Derecho

Disciplinario.Colombia: Instituto de Estudios del Ministerio Público. Procuraduría General de la Nación, 2006. t. 1.

GÓMEZ PÉREZ, ÁngelaEl principio non bis in ídem.Sanciones penales y sanciones administrativas. Bolivia: Fondo Editorial Colegio de Abogados de Cochabamba, 2001.

GONZÁLEZ MonZÓN, Alejandro. Los principios generales del Derecho. Bogotá: Editorial Leyer, 2018.

Govín y TORRes, Antonio. Elementos Teóricos Prácticos del Derecho Administrativo vigente en Cuba. 2. ed. Habana: Imprenta "El Siglo XX", [20-?].

GUZMÁN HERnÁNDEZ, Yan. "La dignidad en la Constitución cubana de 2019 y en dos notas comparadas: dimensiones de análisis y retos para el juez". Revista Cubana de Derecho, Habana, n. 54,2019.

MARCHECo ACUÑA, Benjamín. "El control judicial de la potestad discrecional de la 
Administración Pública en Cuba". Revista Facultad de Derecho y Ciencias Políticas, v. 39, n. $110,2009$.

MARCHECO ACUÑA, Benjamín. Fundamentos de la justicia administrativa. Habana: Ed. UNIJURIS, 2017.

MARINA JALVO, Belén. “Aspectos fundamentales de la configuración actual de la potestad disciplinaria de la Administración Pública española sobre el personal a su servicio”.Revista Derecho \& Sociedad, Perú, n. 54,2020.

MATILla CORREA, AndryLa buena administración como noción jurídico administrativa. Madrid: Ed. Dikynson, 2020.

Matilla Correa, Andry. "Comentarios sobre las fuentes del Derecho Administrativo (excepto el reglamento)": Temas de Derecho Administrativo Cubano. Habana: Ed. Félix Varela, 2004.t. 1.

MejíAs Rodríguez, Carlos A. Derecho Penal Económico. La Habana: Ed. Félix Varela, 2016. p. 18-24.

Mejías Rodríguez, Carlos A. El concepto de funcionario público en Cuba. Un punto de contacto entre el Derecho Administrativo y el Derecho Penal, 30 mayo 2010. Disponible en https://derechopenalonline.com. Acesso en: 20/04/2021

MONZÓN PÁEZ, Fernando. La noción de funcionario público como categoría iusadministrativa: una propuesta para Cuba. Tesis (Doctorado) - en Ciencia Jurídica, Habana, 2020 .

Quiróz Pírez, Renén. Manual de Derecho Penal General. Habana: Ed. Félix Varela,2006. t. 1.

RICHARDS MARTÍNEZ, Orisell. "El agotamiento de la vía administrativa como presupuesto de acceso a la justicia administrativa. Algunas consideraciones desde Cuba". In: AndryMAtILlA; Juan MendozA y Ariel MANTECÓN (coord.).Perspectiva actual del Derecho Procesal (civil y administrativo) en Cuba. Homenaje al profesor Dr. Rafael Grillo Longoria. Habana: Ed.

ONBC, 2016.

RICHARDS MARTíNEZ. Orisell. Los recursos administrativos en Cuba. Fundamentos teóricos de su régimen jurídico.Habana: Ed. ONBC, 2018. p. 144.

RinCÓn CóRDOBA, Jorge I. La potestad disciplinaria en el Derecho Administrativo.

Argentina: Ed. Ijinternational Legal Group, 2018.

Romero Antola, Mario. Los principios del Derecho como fuente el Derecho. Revista LUMEN, España, 2013.

RuIZ y GómeZ, Julián. Principios del Derecho Administrativo. El personal de la Administración Pública. Exposición Doctrinal y de Derecho Positivo y Jurisprudencia cubana. 1. ed. La Habana: Ed. Cultura S.A., 1935.

Trayter, Juan M. Manual de Derecho Disciplinario de los Funcionarios Públicos. Madrid: Ed. Marcial Pons, 1992. 
Villabella Armengol, Carlos M. Estudios de Derecho Constitucional. Habana: Ed. UNIJURIS, 2020. 